\title{
Rise of Big Data Analytics and the Role of Human Resource Management
}

\author{
Farzana Ashraf \\ University of Liberal Arts Bangladesh
}

Even though data-driven organizational practices have gained popularity over time, Human Resource Management (HRM) functions in many organizations are yet to embrace this. As companies have already started implementing Big Data Analytics (BDA) in several other key business functions, there will be a great impact on the quantity and types of jobs along with the skills needed to perform those jobs. Hence, a prodigious extent of responsibility now lies on the shoulders of HRM to connect an organization's digital strategies to its people strategies. The focused area of this paper was to explore through theoretical lenses, how an organization can move towards data-driven HR by adopting Digital HR Planning (HRP) in order to gain competitive advantage over firms that are still practicing conventional HRM. A challenge associated with this could be how this new version of HRP can enhance employee wellbeing without invading their privacy.

Keywords: Big Data Analytics, HR Analytics, Human Resource Planning, Digitization of HR, Employee Well-being, Data-driven HR

\section{INTRODUCTION}

The practice of job cut is expected and accepted in the corporate sector now-a-days. With less longterm orientation, companies tend to "over hire" during the period of expansion and subsequently fire to cope up with organizational crises. As a result of these sudden interventions, employees become insecure and stressed out which ultimately take a toll on their wellbeing. This phenomenon is not just limited to the corporate sector of any specific country. It is an alarming issue in the global context as well. According to an article published in the mailonline on April 10, 2012, Sony has announced 10,000 job losses worldwide, around 6\% of its global workforce (Waugh, 2012). On September 2019, BBC News published a piece of news titled UK tobacco giant BAT to cut 2,300 jobs (BBC News, 2019). The same portal came up with another one in late November that Mercedes-Benz owner Daimler has announced to cut 10,000 jobs worldwide ((BBC News, 2019).

All these aforementioned incidents may refer to one common scenario that these organizations have a group of redundant employees who are no longer required to be in the organization's journey towards goal-attainment. Among many probable reasons, the most logical two reasons could be:

a) These organizations did not have a future-oriented process of Human Resource Planning (HRP) in place that could fit best with the changing business environment and help them plan proactively to avoid talent surpluses and shortages.

b) In this age of digitization, technology has redesigned many of the jobs in such way that it has either eliminated several non-specialized works or created requirement for new sets of skilled tasks for which the current workforce is not ready yet. 
Both the points signal that the organizations need to develop an up-to-date HR Plan that is a) customized as per their business plan for that period and b) in accordance with ongoing and upcoming technological revolution.

\section{LITERATURE REVIEW}

Over the past few decades, Human Resource Management (HRM) has evolved from an administrative-oriented support function to a core strategic business function (Ulrich \& Dulebohn, 2015). Experts have defined Strategic Human Resource Management (SHRM) as the process of forecasting, understanding, transforming, improving and leading human behavior within the organization in line with the strategic plans proposed by the top management (Lojić, 2012). It generally comprises four key functions such as Staffing, Training and Development, Motivation and Maintenance.

In early discussions of Human Resource Planning which falls under the Staffing function, Vetter (1967) defined it as "the process through which management determines how the organization should move from a current manpower arrangement to a more desired arrangement". This shift from current state to the desired state would be possible only when the organizations will regularly assess their current human resource capacity against the capacity needed to achieve the vision, mission and business goals of the organization and develop their HR strategies accordingly. In the subsequent studies, John Gennard (2004) defined Human Resource Planning (HRP) as "Human Resource Planning may be defined as strategy for the acquisition (recruitment/selection), utilization (deployment), improvement (training and development) and preservation (pay and rewards) of an organization's human resources" (Deb, 2006). Prior to him, Decenzo and Robbins (2000) referred to HRP as the process of ensuring that organization has the right number of people, with the right skills, in the right place and at the right time who are capable of effectively and efficiently completing those tasks that will help the organization attain its overall objectives. The latter definition is more from of a strategic point of view as it has got a long-term perspective. Later, contemporary specialists stated that by using Strategic HR Planning, Management aims to have the right number and the right kind of employees, at the right place and at the right time, performing actions which result in long-term benefits to both the employee and the organization (Jackson, 2014). According to Heneman, Judge and Mueller (2003), the process of HRP consists of four chronological steps such as:

- Forecasting the firm's future human resource requirements

- Determining the firm's future human resource availability

- Conducting a gap analysis and

- Developing action plans to fulfill the anticipated gaps

The traditional process of HRP gets transformed into strategic HRP when it can ensure that at the fourth step, the firm has developed action plans in the form of HR strategies that best support its business strategies By studying all these scholarly definitions of Strategic HRP (Nkomo, 1987; Smith, Boroski \& Davis, 1992; Dyer, 1992 and Singh, 2018), it can be clearly stated that Strategic HRP help a firm achieve its business goal. However, integration of technological aspects in HR Planning got ignored in these definitions which might make today's HRM functions lag behind in this era of digital revolution when generation $\mathrm{Z}$ is about to enter into the workforce. At present, when Digitization is decreasing the traditional competitive advantage very fast by taking down the industry barriers, demolishing long-lasting affluent business models (Rometty, 2016), the need of a technology-oriented plan of people management cannot be denied.

Modern technologies such as Big Data Analytics (BDA) are being implemented by organizations in many functional areas including marketing, operations, and finance to produce smart decisions and boost organizational performance (Chen, 2012). According to past and present trends, it is evident that technological revolution will displace knowledge workers just the way industrial revolution has displaced farm workers. However, this does not necessarily mean that technology will replace humans. Many researchers and practitioners have identified that most Artificial Intelligence (AI) oriented applications 
augment, rather than replace, human efforts (Ross, 2018). On one hand, it will obviously eliminate certain tasks, but on the other hand, it might enable people to get free from those traditional tasks and be more involved in value-added work. However, this would certainly need an upgradation of people's skills. AI could profoundly affect $48 \%$ of the American employees who are knowledge workers-and more than 230 million knowledge-worker roles in the global context. But organizations need to restructure the processes of human-machine interaction and redesign jobs (Daugherty, 2018). A research of CIPD shows that $\mathrm{AI}$ and automation are more likely to generate jobs than to eradicate them. This research claims that these modern technologies tend to convert conventional jobs into more complex and interesting ones by providing the employees with more autonomy and control over their work. Since the workplace becomes more rewarding and enjoyable with challenging tasks and balanced work, employee wellbeing increases. Both the aforementioned studies have indicated that to survive this tremendous workplace transformation, an HR plan needs to take both business strategy and technological advancements into consideration. A frequently referred study has found out that businesses that implement big data platform to advise their planning and decision-making activities are on an average 5\% more prolific than their competitors in the same industry who are not using those (McAfee and Brynjolfsson, 2012). Currently, Human Resource Management (HRM) is able to manage a digital workforce in a digital workplace carrying out vital HR functions through digital means (Volini, 2017). Despite this, HRM is not embracing data analytics at a pace similar to that of other business functions even though at present appeal of data-driven HR practices is increasing (Marler \& Boudreau, 2017).

Therefore, based on the shortcomings of previous literature and the scope within the trends of today's organizations, time has come when we should revisit the area of Strategic HR Planning perhaps with a more AI-savvy concept called "Digital HR Planning". This plan will be not only from an organization's business strategy point of view but also from its digital strategy point of view and hence sustainable in the long-term. Digital HR Planning can be attempted to define as "the process of having the right number people with the right set of 'future-ready' skills, at the right place and at the right time, by capitalizing on the impacts of digital technologies which will result in long-term benefits to both the employee and the organization." This can be achieved by aligning a company's HRP process with Big Data Analytics and HR Analytics.

\section{COMPETITIVE ADVANTAGE AND DIGITAL HR PLANNING}

\section{Step 1}

Unlike Strategic HRP that starts from assessing a firm's current HR capacity, Digital HRP (see figure 1) will start from the exploration of hidden patterns and market trends through Big Data Analytics of relevant industries. The firm needs to develop its business plan accordingly and process will end with the origination of data driven HR strategies.

FIGURE 1

\section{DIGITAL HR PLANNING PROCESS}

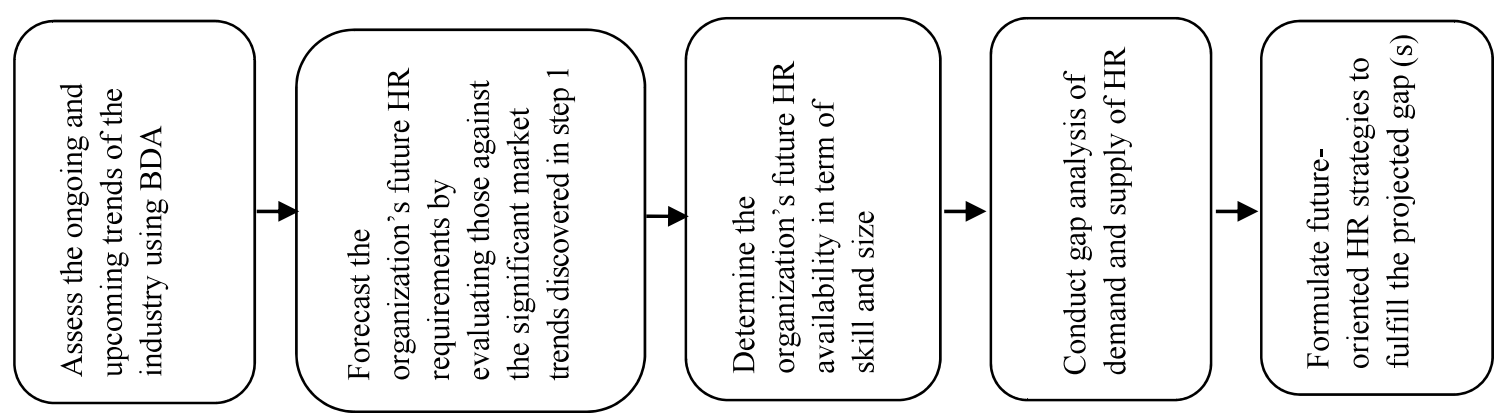




\section{Step 2}

In this step, HR requirement will be forecasted in term of quality and quantity. This step will try to forecast the organization's future HR requirements based on the firm's business plan that captured the market trends identified in step 1. How many employees and what skills would an organization's workforce need to match with the upcoming market trends as well as technological advancements that have been identified through the industry scanning done in step 1? Determination of future HR requirements will have to be carried out by evaluating the industry trends against the organization's business plan and digital plan both. Matching them against Business plan alone will not be able to ensure future-readiness of the workforce during this high-tech period.

\section{Step 3}

This step will assess the organization's future Human Resources' availability in term of size and skills. The organization needs to apply HR Analytics (HRA) in determining the future availability of HR by forecasting employee turnover and their movements along the career path along with a comprehensive assessment current proficiencies and deficiencies in their skills coupled with employee development plan. According to Jones (2014), HRA is an instrument that provides HR practitioners with the necessary data required to make decisions about mitigating high turnover rates, ensuring the quality of new recruits, and improving the predictions related to organizational effectiveness and success.

\section{Step 4}

The organization will conduct gap analysis of demand (step 3) and supply (step 2) of its human resources in this step. The possible outcomes of this step could be a) surplus, b) shortage, and c) equilibrium of Human Resources in term of quantity (i.e. size of workforce) and quality (i.e. skills).

\section{Step 5}

Finally, appropriate HR strategies need to be developed for all the major business functions of the organization to deal with the size and skill gaps identified in step 4. These strategies need to be designed in such a way that they can measure progress at every stage of the employee life cycle and ensure that an organization's workforce has the required sets of future-ready skills to meet its changing business needs and also to survive any forthcoming technological shift.

\section{EMPLOYEE WELL-BEING AND DIGITAL HR PLANNING}

In order to carry out the digital HRP process, an organization's HRM unit needs to be digitized by using a digital platform such as HR Analytics in formulating strategies for the significant functions of HRM such as recruitment \& selection, training \& development, compensation \& benefit, performance management and employee relations.

As yet, HR's practice of big data analytics is mostly limited to hiring related decision makings (Angrave, 2016; McAbee, 2017). However, to ensure higher organizational productivity which is the ultimate objective of any business function, big data analytics should not be restricted to candidate screening only, rather this should focus on creating HR function's strategic alignment with rest of the business functions by determining how HR can enhance the skills and knowledge of employees to gain competitive advantage and enhance organizational performance (Jackson, 2014). When it comes to the use of big data analytics in HR Planning, ethical concerns related to the implementation have a significant role to play as employee data is highly confidential, and organizations need to exercise great deal of care in deciding what data to collect and what to do with this (Cappelli, 2017). Unlike customer analytics where customers are not bound to share their purchasing habits, human resources at a workplace may not have the liberty of not participating in the organization's data collection platform. Hence, the data collected through various social media channels and stored by HR could result in compromised employee privacy (Zwitter, 2014). Since data collected by HR function could be confidential and private in nature 
and include information that cannot be shared (Chen, 2012), an ethical framework needs to be taken into consideration while devising a Digital HR Plan for the organization.

Accrding to Rahmati \& Veiseh (2015) and Gupta \& Sharma (2018), another characteristic of HRP is to produce benefit for both employers and employees. Digital HRP can improve employee well-being as technology-based HR provides employees with a sense of belongingness by attaching them to each other through personal relationships. These personal connections could be problem-solving networks where employees work on common business problems or social networking sites where they share their daily lives (Ulrich, 2019). In addition, generation Z, considered to be the first true digital natives, are about to enter the workforce with completely different priorities, values and needs (Schrith, 2019) and Digital HRP may be a proactive approach to attract and retain them and also to ensure their wellbeing at workplace.

\section{CONCLUSION}

This paper sheds light on how a 'future-oriented' HR planning can incorporate technological aspects in each step of the process that would ultimately make it more equitable and sustainable in the long run. Based on the literature gap identified and framework discussed, further research initiatives can be taken to establish a fact-based assessment of how Digital HR Planning can better equip an organization to gain competitive advantage over competitors and the factors contributing in this shift from conventional HR Planning to Digital HR Planning. Furthermore, additional studies can be undertaken to articulate an ethical framework in which Digital HRP can be practiced without intruding an employee's personal space and hence by ensuring a positive impact on employee wellbeing.

\section{REFERENCES}

Angrave, D., Charlwood, A., Kirkpatrick, I., Lawrence, M., \& Stuart, M. (2016). HR and analytics: why HR is set to fail the big data challenge. Human Resource Management Journal, 26(1), 1-11.

BBC News. (2019, November 29). Mercedes-Benz owner Daimler to cut 10,000 jobs worldwide. Retrieved from https://www.bbc.com/news/business-50598673.

BBC News. (2019, September 12). UK tobacco giant BAT to cut 2,300 jobs. Retrieved from https://www.bbc.com/news/business-49673133.

Cappelli, P. (2017). There's no such thing as big data in HR. Retrieved June 15, 2017.

Chen, H., Chiang, R. H., \& Storey, V. C. (2012). Business intelligence and analytics: From big data to big impact. MIS Quarterly, 36(4).

CIPD. (2019). People and machines: from hype to reality. London: Author

Daugherty, P. R., \& Wilson, H. J. (2018). Human+ machine: reimagining work in the age of AI. Harvard Business Press.

Deb, T. (2006). Strategic approach to human resource management. Atlantic Publishers \& Dist., p. 76.

DeCenzo, D. A., Robbins, S. P., \& Verhulst, S. L. (2000). Fundamentals of Human Resource Management. Binder Ready Version. John Wiley \& Sons.

Dyer, L. (1992). Linking human resource and business strategies. In Human resource planning (pp. 4954). Gabler Verlag.

Gupta, N., \& Sharma, V. (2018). Relationship between leader member exchange (LMX), high involvement HRP and employee resilience on extra-role performance. Journal of Indian Business Research.

Heneman, H. G., Judge, T., \& Kammeyer-Mueller, J. D. (2003). Staffing organizations. Middleton, WI: Mendota House.

Jackson, S. E., \& Schuler, R. S. (1990). Human resource planning: Challenges for industrial/ organizational psychologists. American Psychologist, 45(2), 223.

Jackson, S. E., Schuler, R. S., \& Jiang, K. (2014). An aspirational framework for strategic human resource management. The Academy of Management Annals, 8(1), 1-56. 
Jones, K. (2014). Conquering HR Analytics: Do you need a rocket scientist or a crystal ball? Workforce Solutions Review, 5(1), 43-44.

Lojić, R., Škrbić, Ž., \& Ristić, V. (2012). Strategic approach to human resources management. Theoretical-technical Journal for Protection, Security, Defense, Education and Training, pp. 47-63.

Marler, J. H., \& Boudreau, J. W. (2017). An evidence-based review of HR Analytics. The International Journal of Human Resource Management, 28(1), 3-26.

McAbee, S. T., Landis, R. S., \& Burke, M. I. (2017). Inductive reasoning: The promise of big data. Human Resource Management Review, 27(2), 277-290.

McAfee, A., Brynjolfsson, E., Davenport, T. H., Patil, D. J., \& Barton, D. (2012). Big data: the management revolution. Harvard Business Review, 90(10), 60-68.

Nkomo, S. M. (1987). Human resource planning and organization performance: An exploratory analysis. Strategic Management Journal, 8(4), 387-392.

Rahmati, R., \& Veiseh, S. (2015). Investigating the effect of human resource planning (HRP) on the quality of services of Melli Bank via the mediating variable of employees' service behaviors.

Ross, J. (2018). The fundamental flaw in AI implementation. MIT Sloan Management Review, 59(2), 1011.

Schroth, H. (2019). Are You Ready for Gen Z in the Workplace? California Management Review, 0008125619841006.

Singh, J. (2018). HR Planning. Journal of HR, Organizational Behaviour \& Entrepreneurship Development, 2(1), 40-48.

Smith, B. J., Boroski, J. W., \& Davis, G. E. (1992). Human resource planning. Human Resource Management, 31(1-2), 81-93.

Ulrich, D. (2019, February). Digital HR: What Is It and What's Next? Retrieved from https://rbl.net/insights/articles/digital-hr-what-is-it-and-whats-next.

Ulrich, D., \& Dulebohn, J. H. (2015). Are we there yet? What's next for HR? Human Resource Management Review, 25(2), 188-204.

Vetter, E. W. (1964). The nature of long range manpower planning. Human Resource Management, 3(2), 20-27.

Volini, E., Occean, P., Stephan, M., \& Walsh, B. (2017). Digital HR: Platforms, people, and work. Global Human Capital Trends 2017: Rewriting the Rules for the Digital Age, pp. 87-93.

Waugh, R. (2012, April 10). Sony plunges to \$6.4BN annual loss as Samsung and Apple eat into its businesses - giant cuts 10,000 jobs worldwide. Retrieved from

http://www.dailymail.co.uk/sciencetech/article-2127643/Sony-plunges-6-4BN-annual-LossSamsung-Apple-eat-businesses-giant-cuts-10-000-jobs-worldwide.html.

Zwitter, A. (2014). Big data ethics. Big Data \& Society, 1(2), 2053951714559253. 